\title{
Engagement in Digital Lecture Halls: A Study of Student Course Engagement and Mobile Device use During Lecture
}

\author{
Gwendolyn Witecki and Blair Nonnecke \\ University of Guelph, School of Computer Science, \\ Guelph, Ontario, Canada
}

\section{gduffey@uoguelph.ca, nonnecke@uoguelph.ca}

\begin{abstract}
Universities have experienced increases in technology ownership and usage amongst students entering undergraduate programs. Almost all students report owning a mobile phone and many students view laptops and tablets as educational tools, though they also report using them for nonacademic activities during lectures. We explored the relationship between student course engagement and the use of smartphones, laptops, cell phones, and tablets during lecture. Undergraduate students responded to an online survey asking about both course engagement and mobile device habits. Results show that smartphone use was most strongly related to lowered course engagement and while laptop use was related to lowered engagement, it was to a lesser extent. In contrast, overall engagement of students using tablets or cell phones was not significantly different than those who did not.
\end{abstract}

Keywords: pedagogical issues; post-secondary education; improving classroom teaching; media in education; interactive learning environments; laptops; smartphones; cell phones; tablets; student course engagement; unstructured mobile device use

\section{Introduction}

Recent studies of mobile technology use found that smartphones, laptops, cell phones and tablets are frequently used by students at the post-secondary level (Emanuel, 2013; Grajek, 2011; Pearson Foundation, 2012). For example, in a survey of 403 undergraduate students of varying majors from a single university, $99.5 \%$ of respondents reported owning a mobile phone and $85 \%$ reported the phone they owned was a smartphone (Emanuel, 2013). The same study also found that $74 \%$ of students admitted to using their mobile phone during lectures. Furthermore, a nation-wide

Material published as part of this publication, either on-line or in print, is copyrighted by the Informing Science Institute. Permission to make digital or paper copy of part or all of these works for personal or classroom use is granted without fee provided that the copies are not made or distributed for profit or commercial advantage AND that copies 1) bear this notice in full and 2) give the full citation on the first page. It is permissible to abstract these works so long as credit is given. To copy in all other cases or to republish or to post on a server or to redistribute to lists requires specific permission and payment of a fee. Contact Publisher@InformingScience.org to request redistribution permission. survey of laptop use that included 3000 post-secondary students from 1179 institutions found that approximately $98 \%$ of students owned a mobile computer, with $87 \%$ reporting ownership of a laptop and $11 \%$ reporting ownership of a netbook (Grajek, 2011). In this study, 81\% of respondents reported feeling these devices were useful for their educational pursuits, and a variety of studies have reported high levels of laptop use in lec- 
ture-style courses (e.g., Fried, 2008; Hammer, Ronen, Sharon, Lankry, Huberman, \& Zamtsov, 2010). Lastly, tablet ownership is also becoming more popular amongst undergraduate students; a study of 1206 undergraduates from differing institutions reported that $25 \%$ of participants owned a tablet, up from 7\% in the previous study two years previous (Pearson Foundation, 2010, 2012). Moreover, $64 \%$ of tablet-owners reported that tablets enabled them to perform better during class (Pearson Foundation, 2012). Based on this evidence, mobile device use is clearly pervasive in post-secondary institutions; however, how they are used needs further research.

Much of the current research focuses on the use of mobile devices during lectures, as opposed use during labs and/or seminars. One reason may be the difference in class size between lectures, labs, and seminars. Labs and seminars tend to have fewer students than large lectures, and having fewer students in the classroom is correlated with higher levels of student motivation (Bolander, 1973) and increased student course GPA (Kokkelenberg, Dillon, \& Christy, 2008). Additionally, labs and seminars are often structured with less of a focus on passive content reception and more on active, participatory learning. For these reasons, labs, seminars and lectures are inherently different and findings regarding the nature of mobile device use in one context will not be easily generalizable to another. Furthermore, in contrast to labs and seminars, current research has already identified an existing problem with the use of laptops and other mobile devices during lecture (Fried, 2008; Hembrooke \& Gay, 2003). For these reasons, the current study focuses on the use of mobile devices in large lecture-style classes.

\section{Literature Review}

\section{Unstructured Laptop Use}

Kay and Lauricella (2011) found student participation and interest in courses increased through the use of technology when the device was used to accomplish specific tasks integrated fluidly into a lecture or learning activity. However, they also found that unstructured laptop use was correlated with increased off-task use of technology and reduced on-task use. They defined unstructured laptop use as student-directed use of laptop computers in lectures where the professor largely ignores the use of such technology while delivering course content (often in a traditional lecture-style format) as if laptops were not present in the classroom. In this scenario, individual students are given the freedom to determine for themselves what constitutes appropriate and inappropriate laptop use without the imposition of constraints.

Kay and Lauricella (2011) established that unstructured laptop use is a poor alternative to incorporating laptops into the classroom by comparing on and off task laptop use in both structured and unstructured classroom contexts. Similarly, Fried (2008) conducted a correlational study of a general psychology class delivered in a traditional lecture format in which students were free to use their laptops in an unstructured manner. He then compared laptop users to non-laptop users in terms of distractibility and learning outcomes. The study found that students using laptops were more distracted than those who did not, and that users also scored lower on measures of selfreported lecture understanding.

The study also found that students using laptops in an unstructured setting received lower overall course grades even when factors previously identified as correlated to grades were controlled for, e.g., attendance. Moreover, an experimental study conducted on an upper-year communications course yielded similar results (Hembrooke \& Gay, 2003). They found that students in the unstructured laptop condition performed significantly worse on tests of recognition and recall after a traditionally delivered lecture than the non-laptop control group. In all three studies, the use of an unstructured laptop format was associated with lower performance than either a structured (Kay \& Lauricella, 2011) or laptop-free format (Fried, 2008; Hembrooke \& Gay, 2003). 
Despite evidence that it is a poor alternative, unstructured laptop use remains a common practice in post-secondary institutions (Kay \& Lauricella, 2011). In recent unstructured laptop settings, it is reasonable to assume that the use of other mobile devices such as smartphones, cell phones, and tablets is treated in the same way since the instructor delivers the lecture as if these devices are not present and ignores their use. This paradigm of unstructured mobile device use allows students discretionary freedom of not only how their laptops are used during lectures, but also how their smartphones, cell phones and tablets are used as well. Due to this common practice, it is important to understand the effect unstructured mobile device use has on student engagement with academic material during lectures.

\section{Mobile Technology Use and Student Engagement}

Student engagement can be defined as the time and effort students devote to any behaviour empirically connected to educationally desirable outcomes including academic success, graduation and the development of skills necessary for related employment after graduation (Kuh, 2009). How engagement relates to the use of mobile devices has been studied effectively using a number of tools: the National Survey of Student Engagement (NSSE), which was developed to assess the extent to which university students are engaged in academically relevant activities (CCI Research Inc., 2009); and the College Student Experiences Questionnaire (CSEQ), which was developed to assess students' overall energy devoted to study activities such as reading, writing, and use of information technology (Kuh \& Hu, 2001).

Laird \& Kuh's (2005) study of approximately 350,000 college students from around the United States found a correlation between NSSE's measures of student-faculty interactions, level of academic emphasis and challenge, active and collaborative learning, and laptop usage by students. They concluded that aspects of students' engagement with an institution were positively correlated with laptop use. Similarly, a study of 18,344 college and university students used the CSEQ to measure engagement and determined that information technology use was positively correlated with the effort students devoted to studying and other academic activities overall on campus (Kuh $\& \mathrm{Hu}, 2001)$. These studies stand out because of their large, nation-wide sample sizes as well as their use of well-accepted and defined measurement tools.

\section{Course GPA and Students' Use of Laptops, Cell Phones and Smartphones}

Institution-wide measurements of engagement such as NSSE have been traditionally held to be positively correlated with objective measures of success such as institutional GPA (Carini, Kuh, $\&$ Klein, 2006). However, the results of course-level studies examining the relationship between mobile device use and student gains in individual courses have contradicted the predictions made by positive correlations between institutional engagement and student laptop and Internet use. In a three year experimental study in which course data was gathered for honours business courses, there was no significant difference in overall GPA, writing-intensive GPA, or mathematicsintensive GPA between the laptop-using cohorts and the non-laptop control cohort (Wurst, Smarkola, \& Gaffney, 2008). In this study of 87 honours-level business students, laptops were provided to two incoming cohorts who were compared to a previous, non-laptop using cohort who completed the program in the previous year. However, the study did not differentiate between laptop use in and outside of the classroom.

Three studies examining laptop and Internet usage in an unstructured format further contradict the predictions made by studies of technology use and institutional engagement. A correlational study of 137 students in a general psychology class in which lectures were delivered permitting unstructured laptop use found that increased laptop use was significantly and negatively correlated with 
course GPA, self-reported measures of lecture clarity, attention paid to the lecture, and understanding of course content (Fried, 2008). Moreover, an experimental design including 44 students in a general psychology class found that students in the non-laptop control condition significantly outperformed their laptop-using peers in an after-lecture test of content retention (Hembrooke \& Gay, 2003). In this experiment the same lecture was delivered to two groups, one in which laptops were used in an unstructured format and the other in which no laptops were permitted. The groups were then switched later in the semester as a counter balancing measure.

Lastly, in a study of 82 college students in computing and communications classes, Grace-Martin \& Gay (2001) found a significant and negative correlation between length of browsing sessions during lectures and overall course GPA as well as between the amount of time browsing during class and overall course GPA in courses that used the unstructured laptop format. This study is of particular note for two reasons. Firstly, the study used objective measures of Internet browsing by logging student behaviour online instead of relying on self-report measures or discrete categories, and secondly, the study examined Internet browsing behaviour generally rather than laptop-use specifically which may be generalizable to other devices with access to the Internet. The results of these studies suggest that examination of the relationship between unstructured mobile device use during lectures and student course engagement may yield different results than those studies examining the relationship between institutional mobile device use and student institutional engagement.

\section{The Student Course Engagement Questionnaire}

Handelsman, Briggs, Sullivan, \& Towler (2005) developed an instrument for measuring student engagement within an individual course. The Student Course Engagement Questionnaire (SCEQ) is comprised of four factors found to relate to student course engagement:

(1) Skills Engagement relates to educationally relevant behaviours students initiate to advance their academic work

(2) Emotional Engagement reflects how much students think about material outside of class and use it in their everyday life

(3) Participation/Interaction Engagement represents how often students are involved in classroom discussions or activities

(4) Performance Engagement encompasses how confident students feel in evaluation situations and how satisfied students are with their grades

\section{SCEQ and Students' Use of Laptops, Cell Phones and Smartphones}

Skills engagement reflects how engaged the student is at practicing the skills and knowledge required for a given course (Handelsman et al., 2005). Skills engagement is the most clearly affected by smartphone, laptop, cell phone and tablet use in the classroom. For example, in a weekly student survey of in-lecture habits, increased time spent using a laptop was negatively correlated with how much attention students reported paying to the lecture (Fried, 2008). Additionally, multiple studies have reported high rates of students using mobile devices such as smartphones, laptops and cell phones during class for uses unrelated to course objectives (Fried, 2008; Hammer et al., 2010; Hembrooke \& Gay, 2003; Kraushaar \& Novak, 2010; Kulesza, DeHondt, \& Nezlek, 2010; Watson \& Barber, 2008; Wurst et al., 2008). Research suggests skills engagement is negatively correlated with unstructured in-class technology use.

Emotional engagement consists of ways students involve course material in their life beyond the confines of the course and how relevant a student feels the course is to his/her life. This category 
is difficult to assess based solely on behaviours observable in class as it is largely internal to the individual and outside the classroom (Handelsman et al., 2005). Very little research has explored the relationship between emotional engagement and unstructured technology use in class. Kulesza et al. (2010) argue that using laptops and mobile phones lowers interest in course material by focusing attention on using a device and not on learning the material. Another study showed $97 \%$ of laptop users cited boredom as the reason for their off-task use (Hammer et al., 2010). This statistic suggests that emotional disengagement may promote course-irrelevant use of information technology. In support of this hypothesis, Mann \& Robinson (2009) found 45.5\% of bored students used phones to amuse themselves. Further study is required on the impact of unstructured in-class use of mobile devices on emotional engagement.

Participation engagement represents the ways in which a student actively participates and interacts with peers and instructors in class (Handelsman et al., 2005). There is little formal research into the relationship between unstructured mobile device use and classroom interaction, but there are some noteworthy findings. Wurst et al. (2008) found laptops increased the number of questions asked by the professor that students were able to answer in-class with current information. Professors in Wingard's (2004) study felt student comfort among peers improved in class, but no change in discussion was noted. In contrast, Kulesza et al. (2010) argue mobile devices in the classroom decrease participation in class. None of these studies were based on empirically gathered participation data, demonstrating a need for further research on the relationship between unstructured use of smartphones, laptops, cell phones and tablets during lectures and participation engagement.

Performance engagement encompasses an individual's self-efficacy in achieving educational goals and confidence in their ability to succeed in course evaluations (Handelsman et al., 2005). How smartphones, laptops, cell phones and tablets impact performance engagement is largely unknown as studies have not focused on this relationship. Further research is required to determine the effect unstructured use of mobile devices has on performance engagement.

\section{Current Study}

Our study explores the relationship between student course engagement and unstructured mobile device use during lectures, and how mobile device use is related to the four engagement factors as described by the SCEQ (Handelsman et al., 2005).

\section{Methods and Materials}

\section{Participants}

Participants were 972 undergraduate students from the University of Guelph, of which $70.88 \%$ (689 participants) were female. All participants attended lecture-style courses running during the regular Autumn 2012 semester from September to December. During lectures, mobile devices such as smartphones, laptops, cell phones, and/or tablets were used at the student's discretion and without instructor guidance or integration. Classes eligible to participate were held at the University of Guelph in lecture theatres with minimum capacities of 150 students. Class sizes ranged from 120 students to 600 students with an average class size of 278 students. In total, 23 classes were invited to participate, of which $78 \%$ were first and second year classes and $22 \%$ were third and fourth year classes. Invited courses were from a variety of departments and respondents represented a wide selection of majors available on campus. A total of 972 students filled out surveys, of which 902 surveys were used in the analysis. 68 surveys were incomplete and two entries were removed due to errors in filling out the survey. Approximately 7000 students heard the invi- 
tation to participate making the response rate approximately $15 \%$. Response rate is reported as an approximation because it was not possible to measure the attendance of classes visited and it is unlikely that every student registered in each course attended when the invitations were delivered. In addition, some students may have heard the invitation in multiple courses; this is unaccounted for in the reported response rate.

\section{Instruments and Measures}

The singular measure consisted of an online survey participants self-administered at a time and place of students' choosing. The measure was divided into two parts: (1) the SCEQ and (2) a survey of student information technology habits during lectures (See Handelsman et al., 2005 for the SCEQ and the Appendix for the survey of technology use). The SCEQ was developed to assess behaviours and attitudes at the course level, focusing in particular on events that occur in and around classes and coursework, as course engagement is theorized to differ between independent courses (Handelsman et al., 2010). The SCEQ is comprised of four factors encompassing both behavioural and affective components of student course engagement. The SCEQ was developed through an interview study of 266 undergraduates and faculty seeking descriptions of the actions, thoughts, and feelings of engaged students in undergraduate courses (Handelsman et al., 2005). The results yielded 27 items that were related to student engagement, of which 23 were unique. A factor analysis of these 23 items yielded the four factor model discussed in The Student Course Engagement Questionnaire section with the four factors together accounting for $43 \%$ of the variability amongst self-reported engagement. Each factor also presented with strong reliability, with alpha values ranging from .76 to .82. The 23-item SCEQ survey measures the four aspects of student course engagement using a five-point Likert scale.

The engagement factors of the SCEQ have been found to correlate with high levels of engagement, with skills engagement having a particularly strong association with positive learning outcomes. For example, Svanum \& Bigatti (2009) found behavioural measures based on Handelsman et al.'s (2005) definition of skills engagement reliably predicted not only GPA, but also whether or not students would graduate with a degree and how quickly they would complete their education. Furthermore, the predictive value of skills engagement on grades and degree completion was found to be significant even when other factors such as SAT scores, student academic background, and GPA from the previous semester were controlled for. Moreover, measures of the SCEQ were negatively correlated with measures of student boredom during lectures (Mann \& Robinson, 2009), a commonly reported reason for using a laptop or phone for non-academic activities (Hammer et al., 2010; Mann \& Robinson, 2009). The SCEQ has been used to measure engagement in a variety of undergraduate settings with similarly high degrees of success (Floyd, Harrington, \& Santiago, 2009; Mandernach, 2009; Mann \& Robinson, 2009; Young \& Bruce, 2011) and is considered to be an effective instrument for capturing the multi-dimensional concept of student course engagement (Mandernach, Donnelli-Sallee \& Dailey-Hebert, 2011).

In addition to the SCEQ component of the survey, students were asked to report on their mobile device habits. They were asked how regularly they bring laptops, tablets, smartphones and cell phones to class, and how those devices were used during the last class attended. Options for device use included taking notes, reading the course outline or lecture notes posted by the professor, reading material related to the course not posted by the professor, commenting on or discussing the content of the current lecture, arranging to meet with peers outside of class for classwork, working on an assignment, email, SMS/text messaging (For phones) or IM (For laptops or tablets), social networking, watching videos, surfing the Internet (not including social networking and video sites), arranging to meet socially with peers outside of class, playing games, and other (please specify). The survey took approximately five to ten minutes for students to complete. 


\section{Method}

A cluster convenience sample was used to invite undergraduate students to participate in the SCEQ and mobile device use survey. Professors of eligible courses were contacted the week before the beginning of the semester with an email requesting permission to visit his or her lecture and invite the class to participate. Professors posted an invitation to participate on their course websites. 23 class requests to participate took place between Monday, October 1 and Friday, November 9,2012 in order to give students an opportunity to settle into their class routines and to be assessed, in order to measure performance engagement accurately. As an incentive to complete the survey, participants could enter into a draw for one of several \$25 gift cards. Students reached the online survey by following a URL posted on their course websites. Every participant agreed to having read and understood the informed consent document before completing the survey.

A Mann Whitney U test was used to compare overall engagement as well as each engagement factor for users and non-users of each mobile device. The groups were self-identified according to device usage during the last class and were, therefore, not randomly assigned. A Mann Whitney $\mathrm{U}$ was used because the responses to each of the engagement questions were ratings on a likert scale of agreement, and a Mann Whitney U treats these data as ordinal despite students' varying perceptions of the difference between each response on the scale (e.g., the difference between agree and strongly agree may vary between students).

\section{Results}

\section{Mobile Device Use During Lectures}

Mobile technology in the classroom was pervasive, with $93 \%$ of students bringing at least one mobile device to one or more lectures each week, and $43.6 \%$ bringing at least one mobile device to every lecture (device options included smartphone, laptop, cell phone, and tablet). Though students brought an average of 1.4 devices to the last lecture attended, not all students brought mobile devices to class. $12.2 \%$ of students claimed not to have used any devices during the last lecture attended, and $7.0 \%$ of students reported they never bring any devices to class with them.

Smartphones were the most commonly carried and used device; $64.8 \%$ of respondents used a smartphone during their last lecture (see Figure 1). Additionally, 33.3\% said they bring a smartphone to every class and $69.4 \%$ said they bring a smartphone to class at least once a week. Only $30.9 \%$ reported never bringing a smartphone to class. Tablets were the least common de-

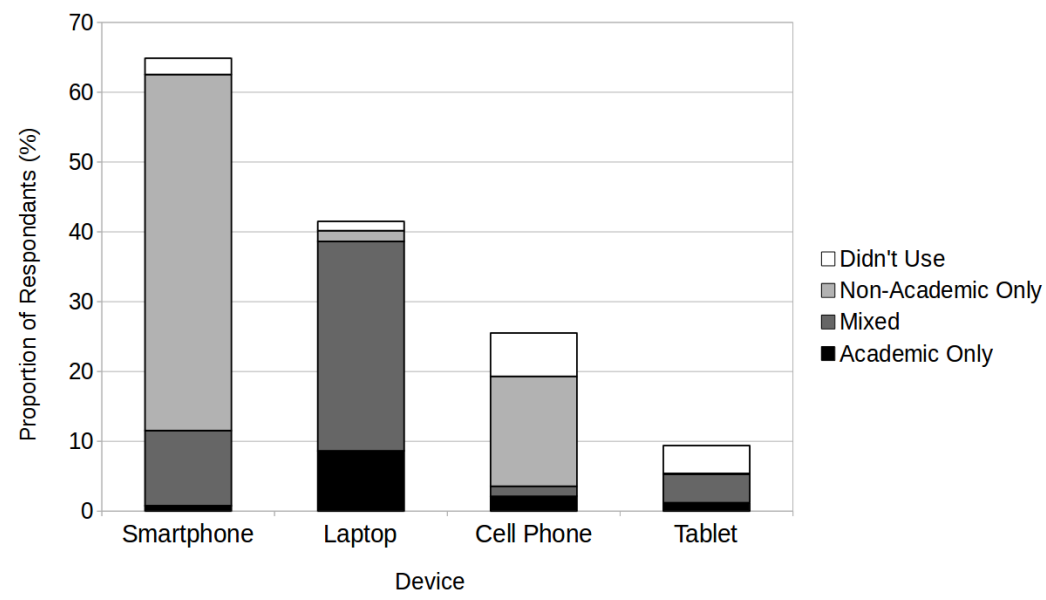

Figure 1: Student Device Use by Device and by Usage Type 
vice. Only $9.4 \%$ of respondents reported tablet usage during the last class and $90.2 \%$ said they never bring a tablet to class. Figure 1 shows the proportion of students who reported using each device for academic compared to non-academic use. Table 1 provides a finer grained breakdown of usage by activity. The three most commonly reported uses for mobile devices were text messaging $(72.7 \%)$, taking notes $(62.5 \%)$ and social networking $(45.9 \%)$.

\begin{tabular}{|l|l|l|l|l|l|}
\hline \multicolumn{5}{|c|}{ Table 1: Student Device Use By Activity } \\
\hline $\begin{array}{l}\text { Activity } \\
\text { Grey= Unrelated to Course Goals } \\
\text { Bold= High/Low }\end{array}$ & $\begin{array}{l}\% \text { of All } \\
\text { Students } \\
\text { (Any De- } \\
\text { vice) }\end{array}$ & $\begin{array}{l}\% \text { of } \\
\text { Laptop } \\
\text { Users }\end{array}$ & $\begin{array}{l}\text { Tablet } \\
\text { Users }\end{array}$ & $\begin{array}{l}\text { \% of } \\
\text { Smart- } \\
\text { phone } \\
\text { Users }\end{array}$ & $\begin{array}{l}\text { Cellphone } \\
\text { Users }\end{array}$ \\
\hline (1) SMS/Text Messaging & $\mathbf{7 2 . 7 \%}$ & - & - & $\mathbf{8 9 . 9 \%}$ & $\mathbf{7 0 . 0 \%}$ \\
\hline (2) Taking Notes & $62.5 \%$ & $\mathbf{8 5 . 1 \%}$ & $38.8 \%$ & $1.7 \%$ & $1.4 \%$ \\
\hline $\begin{array}{l}\text { (3) Social Networking (Including Facebook, } \\
\text { Twitter, etc) }\end{array}$ & $45.9 \%$ & $56.5 \%$ & $25.9 \%$ & $44.4 \%$ & $6.6 \%$ \\
\hline (4) Email & $42.5 \%$ & $58.9 \%$ & $37.6 \%$ & $31.9 \%$ & $1.9 \%$ \\
\hline $\begin{array}{l}\text { (5) Reading the Course Outline or Course } \\
\text { Notes Posted on the Course Website }\end{array}$ & $39.5 \%$ & $80.3 \%$ & $\mathbf{4 0 . 0 \%}$ & $4.1 \%$ & $<\mathbf{1 \%}$ \\
\hline (6) Surfing the Internet & $23.2 \%$ & $33.1 \%$ & $18.8 \%$ & $13.0 \%$ & $1.4 \%$ \\
\hline $\begin{array}{l}\text { (7) Reading Material Related to the Course } \\
\text { Other than the Outline or Notes }\end{array}$ & $23.1 \%$ & $42.9 \%$ & $28.2 \%$ & $4.8 \%$ & $<\mathbf{1 \%}$ \\
\hline $\begin{array}{l}\text { (8) Arranging to Meet with Peers Outside of } \\
\text { Class Socially }\end{array}$ & $16.3 \%$ & $5.1 \%$ & $4.7 \%$ & $18.9 \%$ & $10.8 \%$ \\
\hline (9) Working on an Assignment & $11.2 \%$ & $23.2 \%$ & $4.7 \%$ & $1.4 \%$ & $<\mathbf{1 \%}$ \\
\hline $\begin{array}{l}\text { (10) Playing Games } \\
\text { (11) Arranging to Meet with Peers Outside } \\
\text { of Class Academically }\end{array}$ & $9.7 \%$ & $5.9 \%$ & $\mathbf{2 . 4 \%}$ & $9.9 \%$ & $4.7 \%$ \\
\hline $\begin{array}{l}\text { (12) Instant Messaging } \\
\text { (13) Discussing the Current Lecture }\end{array}$ & $5.9 \%$ & $10.1 \%$ & $5.9 \%$ & $1.5 \%$ & $<\mathbf{1 \%}$ \\
\hline etc) Watching Videos (Including YouTube, & $\mathbf{2 . 8 \%}$ & $\mathbf{4 . 3 \%}$ & $4.7 \%$ & $<\mathbf{1 \%}$ & $<\mathbf{1 \%}$ \\
\hline
\end{tabular}

\section{Smartphone Use}

$64.8 \%$ of respondents brought a smartphone to their last lecture and $86.2 \%$ brought either a smartphone or cell phone to class at least once a week. Of those reporting smartphone usage, $17.7 \%$ used a smartphone for at least one purpose related to course goals and $95.2 \%$ used a smartphone for at least one purpose unrelated to course goals. Table 1 shows the three most commonly reported smartphone tasks were SMS or text messaging (89.9\%), social networking $(44.4 \%)$ and email (31.9\%). Of those who brought a smartphone to class, only $3.6 \%$ reported not using it. 
In terms of overall engagement, smartphone users were significantly less engaged $Z=-5.34$, $\mathrm{p}<.001$, than non-users with the mean rank equal to 384.23 for students with smartphones and 477.39 for students without (see Table 2). Students using smartphones reported significantly less skills engagement $Z=-4.40, p<.001$, than students who did not, with the mean rank equal to 407.51 for smartphone users 485.84 for abstainers. Additionally, smartphone users reported significantly less emotional engagement $Z=-4.15, \mathrm{p}<.001$ than non-users, with the mean rank equal to 416.80 for those using smartphones and 491.12 for those who did not. Participation engagement showed a similar pattern, with smartphone users reporting significantly lower levels of participation engagement $Z=-4.21, p<.001$, than abstainers with the mean rank equal to 415.45 for those using smartphones and 490.83 for those who. Moreover, performance engagement showed an association to smartphone use. Smartphone users reported significantly lower performance engagement, $\mathrm{Z}=-3.81, \mathrm{p}<.001$, than non-users, with the mean rank equal to 421.52 for smartphone users and 489.71 for abstainers. The mean overall engagement rating for students who used a smartphone during class was 3.34 (out of 5) compared to a mean overall engagement rating of 3.53 for students who did not use one. In total, 654 students reported using a smartphone during a lecture in their current course and 318 students reported not using one.

\begin{tabular}{llllll}
\hline \multicolumn{5}{c}{ Table 2: Summary of Findings } \\
$\begin{array}{lllll}\text { Mobile De- } \\
\text { vice }\end{array}$ & $\begin{array}{l}\text { Difference in } \\
\text { Overall En- } \\
\text { gagement }(\mathrm{Z})\end{array}$ & $\begin{array}{l}\text { Difference in } \\
\text { Skills En- } \\
\text { gagement }(\mathrm{Z})\end{array}$ & $\begin{array}{l}\text { Difference in } \\
\text { Emotional En- } \\
\text { gagement }(\mathrm{Z})\end{array}$ & $\begin{array}{l}\text { Difference in } \\
\text { Participation } \\
\text { Engagement } \\
(\mathrm{Z})\end{array}$ & $\begin{array}{l}\text { Difference in } \\
\text { Performance } \\
\text { Engagement } \\
(\mathrm{Z})\end{array}$ \\
\hline Laptops & $-2.23^{*}$ & $-2.61^{* *}$ & -1.18 & -1.04 & -.45 \\
Tablets & -1.05 & -1.55 & -.43 & -.85 & $-2.16^{*}$ \\
Smartphones & $-5.34 * * *$ & $-4.40^{* * *}$ & $-4.15^{* * *}$ & $-4.21^{* * *}$ & $-3.81^{* * *}$ \\
Cell phones & -1.83 & -1.67 & -1.95 & -.59 & -.54 \\
\hline Italics = approached significance & $*=$ significant at .05 & $* *=$ significant at $.01 \quad * * *=$ significant at .001
\end{tabular}

\section{Laptop Use}

$31.3 \%$ of students reported bringing a laptop to every class and $55.3 \%$ reported bringing a laptop to at least one lecture a week. $41.5 \%$ reported bringing a laptop to the last attended lecture. Of those students who reported using a laptop in class, $92.8 \%$ reported using it for at least one purpose related to course goals and $76 \%$ reported using it for at least one purpose unrelated to course goals. As shown in Table 1, the three most commonly reported activities performed on laptops were taking notes $(85.1 \%)$, reading the course outline or course notes provided on the course website $(80.3 \%)$ and email $(58.9 \%)$.

Laptop users were significantly less engaged overall $Z=-2.23, p<.05$ than abstainers (see Table 2). Skills engagement was also observed to be significantly lower $Z=-2.61, p<.01$ for laptop users than abstainers. The mean overall engagement rating of laptop users was 3.37 (out of 5) compared to a mean overall engagement rating of 3.43 for non-laptop users. In total, 443 students reported using laptops during a lecture in their current course compared to 529 students who reported not using one. 


\section{Cell Phone Use}

$5.4 \%$ of respondents brought a cell or feature phone to every class and $26.1 \%$ brought a cell phone to class at least once a week. $23.6 \%$ brought a cell phone to their last lecture. Of those reporting cell phone usage, $7 \%$ used a cell phone for at least one purpose related to course goals and $72.8 \%$ used a cell phone for at least one purpose unrelated to course goals. Table 1 shows the three most commonly reported cell phone tasks were SMS or text messaging (70.0\%), arranging to meet with peers socially outside of class $(10.8 \%)$ and social networking $(6.6 \%)$.

The difference in engagement found between cell phone users and non-users approached significance $Z=-1.83, p=.07$, with the mean rank equal to 388.98 for cell phone users and 425.34 for abstainers (see Table 2). The difference in both skills engagement and emotional engagement approached significance. Skills engagement was found to be lower $\mathrm{Z}=-1.67, \mathrm{p}=.09$, for cell phone users than non-users, with the mean rank equal to 409.15 for cell phone users and 442.83 for abstainers. Emotional engagement was also found to be lower $Z=-1.95, p=.051$, for phone users compared to non-users, with the mean rank equal to 412.71 cell phone users and 452.19 for nonusers. The mean overall engagement rating for students who used a cell phone was 3.35 (out of 5) compared to a mean overall engagement rating of 3.42 for students who did not. In total, 281 students reported using a cell phone during a lecture in their current course and 691 students reported not using one.

\section{Tablet Use}

$3.3 \%$ of respondents brought a tablet to every class and $6.8 \%$ reported bringing a tablet to class at least once a week. $9.4 \%$ brought a tablet to their last lecture; however $42.4 \%$ of tablet carriers reported not using it. Of those reporting tablet usage, 56.5\% used it for at least one purpose related to course goals and $44.7 \%$ used it for at least one purpose unrelated to course goals. Table 1 shows the three most commonly reported tablet activities were reading the course outline or course notes provided on the course website $(40.0 \%)$, taking notes $(38.8 \%)$ and email $(37.6 \%)$. No significant difference was found $\mathrm{Z}=-1.05, n s$, in overall engagement between students who used a tablet compared to those who did not (see Table 2). Performance engagement, however, was significantly lower $\mathrm{Z}=-2.16, \mathrm{p}<.05$, for tablet users than for abstainers. The mean overall engagement rating of tablet users was 3.36 (out of 5) compared to a mean overall engagement rating of 3.41 for students who didn't use one. In total, 153 students reported using a tablet during a lecture in their current course and 819 students reported not using one. A summary of findings by device is given in Table 2 .

\section{Conclusions}

\section{Discussion}

While every device showed a negative correlation with student engagement across all factors, not all correlations were significant (see Table 2). One of the most important findings was the significant negative correlation between smartphone use and student course engagement in all factors, including overall engagement. Laptops also showed a significant negative correlation with overall engagement, but may be mediated by the difference in skills engagement more than any other factor. Other devices did not demonstrate significant correlations, with the exception of tablets, which showed a significant negative correlation with performance engagement, but not overall engagement.

The smartphone findings are notable due to the strength of correlation, the corresponding drop in engagement levels in all factors, and the observation that smartphones were the only device with 
this pattern. Furthermore, evidence from the current study shows that smartphones are uniquely likely to be used exclusively for leisure activities or for socialization during lectures (See Figure 1). Only $18 \%$ of the students used them for a course-related purpose and none of the top five reported uses of this device were related to course goals. What remains unanswered, however, is whether it is disengagement that causes students to turn to smartphone use during class or whether it is the availability of these devices that causes students to disengage. As this study is correlational in nature, it is unable to determine the direction of the relationship.

The finding that laptop use is significantly and negatively correlated with overall engagement, and skills engagement in particular, is similar to previous studies where laptop use during lectures was correlated with a decrease in overall GPA, reduced attention paid in class, and lowered retention or understanding of course material (Fried, 2008; Grace-Martin \& Gay, 2001; Hembrooke \& Gay, 2003). However, despite laptop use being correlated with lower overall course engagement in our study, laptops were also the most commonly used device for course-related goals and their use was associated with lowered engagement in only a single factor, skills engagement.

Additionally, since laptop-using students did not show a difference in factors such as motivation to apply course material to life outside the classroom, participating in discussions during lectures, and self-efficacy on evaluations like users of smartphones, it is possible that the correlation between lowered overall engagement and laptop usage was mediated by a student's skills engagement. Skills engagement is measured by frequency of engaging in course activities such as taking notes and paying attention in class, so it is possible that the negative correlation between engagement and laptop use was restricted to students who chose to use a laptop for course unrelated purposes, thus decreasing the amount of time spent on activities such as taking notes and paying attention in lectures. Moreover, if a distinction between related and unrelated usage could effectively be made, laptop users genuinely engaged in lecture material and using their laptop to learn may have had a moderating effect on the current results. It is possible that using a laptop for course unrelated purposes could show a correlational engagement pattern similar to individuals who use smartphones. In contrast, using a laptop strictly for taking notes or other course-related pursuits may show no difference in engagement, or perhaps even a higher level of engagement as compared to students who choose not use laptops.

Tablet use showed an interesting pattern of reduced engagement. In this case, there was no significant correlation between overall engagement and tablet use, but there was a significant negative correlation between tablet use and performance engagement. This result is interesting because performance engagement is not strictly related to a student's objective success measures, but rather to students' self-efficacy regarding their ability to achieve desired goals and their perception of how they met those goals from a grade perspective. In other words, it is entirely possible to have excellent grades and low performance engagement, e.g., if a student is unhappy with their own success or doesn't believe they can achieve those grades in future. The finding that tablet use is correlated with reduced performance engagement suggests that early technology adopters may lack confidence in their own academic skills and are looking for ways to improve their academic success through the use of technology. Support for this view comes from our finding that tablets are brought to class much less frequently than laptops and by previous findings showing that younger students believe that tablets are academically useful and likely to improve one's ability to succeed in post-secondary education (Pearson Foundation, 2012).

Similarly, cell phone use was not significantly associated with a reduction in overall course engagement. The majority of students did not use a cell phone during class, with less than a quarter of respondents reporting using a cell phone during their last lecture. Cell phones may not have an association with reduced course engagement due to the fact that their functionality is more limited than smartphones and are, for the most part, incapable of accessing the Internet (fewer than $2 \%$ of respondents used a cell phone to browse the Internet, and less than $10 \%$ of respondents reported 
using a cell phone for social networking). Cell phones may have been brought to class primarily as a communications device for before and after class and may be perceived as safety devices more than social devices, e.g., for calling for help in an emergency on the way to or from class.

\section{Implications for Future Research}

The current study should be considered in light of some of its limitations. Firstly, this study relied on self-reported data rather than objectively measured device use. Krashaar and Novak (2010) compared student reported laptop use with laptop use logs and found that students had a tendency to underreport their laptop use. As our study relied on student reported data, the results may be underreporting technology usage and thus possible correlations. Secondly, students reporting the use of one device may have also reported using additional devices in class. However, the current study treated each device as if it were used independently. As a consequence, results may have differed had multiple device use been taken into account. For example, students who used a laptop and a smartphone may have shown a different pattern of engagement as compared to students who used a laptop exclusively. In addition, it is possible that responses garnered were primarily from students who are more readily engaged, or who strongly prefer to use or not use mobile devices during class. Lastly, the current study was of correlational design, and thus cannot determine causal relationships.

Future research that extends the current research by improving on the methodology will be useful. For example, future research could include measurable or observable behavioural data such as Kraushaar and Novak's (2010) study involving the voluntary installation of tracking software onto students' laptops. Additionally, studies focusing on the use of individual devices will be beneficial in determining the effects of each one and help to understand the relationship between simultaneous device use and student course engagement. Additionally, experimental designs are needed to determine whether disengagement is caused by the availability of certain mobile devices or whether the increased use of mobile devices is caused by previously existing disengagement. Additional research examining the relationship between how laptops are used and student course engagement should also be fruitful. As previously discussed, the relationship between laptop use and student course engagement appears to be mediated by the relationship between laptop use and skills engagement. Studies examining skills engagement, overall engagement and type of laptop use could uncover a relationship between the type of usage and course engagement.

Other research should examine the motivations behind students' decisions to bring mobile devices to class. Of the students who brought either a laptop or smartphone to class, almost all respondents reported using them during the lecture. In contrast, many students who brought tablets or cell phones to class reported not using them (see Figure 1). The difference between devices brought and used and devices brought but not used may lie in differences in the each device's unique combination of utility and mobility. Laptops, though more burdensome to carry, are regarded as academically useful with their full array of applications and functions and large screen and keyboard. If students are motivated to bring a laptop to class, they may be more likely to use it. In contrast, smartphones are brought everywhere and may be viewed as a safety or social necessity. Additionally, these very portable devices are also richly functional, and our results show that when these devices are brought to class they tend to be used. In comparison, both cell phones and tablets were frequently brought to class and not used. Cell phones have limited functionality and as a result may get less use during class. While tablets are functionally rich, they are relatively new to the classroom and their usefulness as an academic tool has not been well established. Further research should shed light onto why students decide to bring devices to class and whether and how they are used. 
Lastly, research which addresses whether or not the relationship between laptop use during lectures and student course engagement is mediated by a student's skills engagement will likely prove fruitful. In the current study, $20 \%$ of laptop users reported using their laptop exclusively for academic purposes, and an additional $72 \%$ reported that they used their laptop for at least one task relevant to the course (see Figure 1). It is possible that students who choose to use their laptop for academic purposes only do not show the same significant negative correlation with overall engagement that was demonstrated in the current study. Evidence for such an engagement pattern may further explain the discrepancy noted in the literature between findings linking information technology use and increased institutional engagement (Kuh \& Hu, 2001; Laird \& Kuh, 2005) and findings linking similar use to reduced in-course GPA (Fried, 2008). Our study demonstrates that lowered engagement during lectures is a plausible potential explanation for why previous research identified student technology during lectures use as being negatively correlated with achieving positive course outcomes (Fried, 2008; Grace-Martin \& Gay, 2001; Hammer et al., 2010; Hembrooke \& Gay, 2003; Kay \& Lauricella, 2011). It does not, however, demonstrate any kind of causal relationship or explain why a correlation between mobile device use and reduced engagement would be present within the scope of a course, but not the scope of an institution. Further research that seeks to explain these issues would be beneficial.

\section{Implications for Pedagogy}

Our study demonstrated that unstructured use of some mobile devices correlated with reduced overall engagement as well as reduced course engagement in specific factors, however structured device use in the classroom encompasses a non-trivial amount of research and is beyond the scope of the current research to discuss. Additionally, despite structured mobile device use being recommended, many situations currently exist in which unstructured mobile device use is the reality (Kay \& Lauricella, 2011). Based on our findings, the following describes device specific recommendations for handling unstructured use of mobile devices during lectures.

The smartphone was most strongly correlated with reduced student course engagement. Only $18 \%$ of students used smartphones for academic purposes. Only $2 \%$ of students reported using it to take notes and fewer than 5\% reported using it to view course notes. Moreover, all five of the top five most commonly reported smartphone uses were unrelated to course goals. This evidence suggests that restricting smartphone use during lectures should not disrupt participation in the course and may be educationally beneficial.

In contrast, laptops were often used for course-related goals despite their use being significantly correlated with reduced overall course engagement. However, laptop use was correlated with significantly reduced engagement in only one factor, skills engagement. This correlation may be mediated by whether a student uses his or her laptop to engage with the course during lectures. If further research supports this prediction it may be unwise to restrict laptop use for all students as it would disrupt normal academic functioning for some.

Furthermore, the finding that laptops were the most commonly used device for course-related purposes and that three of the five most commonly reported uses were academic provide evidence that a general restriction or ban could disrupt academic behaviours for many students. At the same time, there is also evidence of a significant proportion of students who use their laptops for activities unrelated to the course. For example, $56 \%$ of all laptop users reported using social media during lectures and 33\% reported surfing the Internet. Since there appears to be a distinction between students who use laptops academically and those who do not, it is recommended that laptop use be limited only when a student has demonstrated an inability to use the device for course-related goals such as taking notes and exhibit self-control in choosing not to use the device for other purposes. 
Cell phones did not have a significant correlation with reduced course engagement; however, students did not use cell phones to complete academically relevant tasks either. Fewer than $2 \%$ of students used a cell phone to take notes or read course notes and four out of the five most commonly reported uses were unrelated to course goals. With no association with reduced overall course engagement, it is recommended that restriction of cell phones during lectures be assessed on a course-by-course basis at the discretion of the instructor. This recommendation is further supported by the finding that fewer than $10 \%$ of students reported bringing a cell phone to every lecture and fewer than $25 \%$ of students reported bringing a cell phone to their most recent lecture.

Tablet use was not significantly correlated with reduced overall course engagement and the number of students bringing a tablet to lectures was relatively low, with $90 \%$ of students reporting never bringing a tablet to lectures. In addition, three of the top five most commonly reported uses for a tablet were academic in nature and included taking course notes and reading lecture slides or course notes. Considering the lack of evidence linking tablet use to reduced course engagement, and that the device is most frequently used for academic purposes, it is recommended that stu-

dents be allowed to use tablets during lectures. This recommendation may need to be re-evaluated if tablets become more popular and more students start to use them for course unrelated purposes.

In summary, while unstructured mobile device was correlated with reduced course engagement, it appears to be mediated by device type and potentially by usage type. It is recommended that courses be assessed independently for the possible impact of different devices on student engagement.

\section{References}

Astin, A. (1993). What matters in college? Four critical years revisited. San Francisco, CA: Jossey-Bass.

Bolander, F. (1973). Class size and levels of student motivation. The Journal of Experimental Education, $42(2), 12-17$.

Carini, R. M., Kuh, G. D., \& Klein, S. P. (2006). Student engagement and student learning: Testing the linkages. Research in Higher Education, 47(1), 1 -32.

CCI Research Inc. (2009). Measures of student engagement in postsecondary education: Theoretical basis and applicability to Ontario's colleges. Toronto: Higher Education Quality Council of Ontario.

Emanuel, R. (2013). The American college student cell phone survey. College Student Journal, 47(1).

Floyd, K., Harrington, S., \& Santiago, J. (2009). The effect of engagement and perceived course value on deep and surface learning strategies. Informing Science: The International Journal of an Emerging Transdiscipline, 12(10), 181-190. Retrieved from http://www.inform.nu/Articles/Vol12/ISJv12p181190Floyd530.pdf

Fried, C. B. (2008). In-class laptop use and its effects on student learning. Computers \& education, 50(3), $906-914$.

Grace-Martin, M., \& Gay, G. (2001). Web browsing, mobile computing and academic performance. Educational Technology \& Society, 4(3).

Grajek, S. (2011). The current state of college students and technology 2011. Presentation at the 2011 EDUCAUSE Center for Applied Research Symposium, Chicago, IL, July 29, 2011. Available from http://www.educause.edu/ecar

Hammer, R., Ronen, M., Sharon, A., Lankry, T., Huberman, Y., \& Zamtsov, V. (2010). Mobile culture in college lectures: instructors' and students' perspectives. Interdisciplinary Journal of Knowledge and Learning Objects, 6, 293-304. Retrieved from http://www.ijello.org/Volume6/IJELLOv6p293304Hammer709.pdf 
Handelsman, M. M., Briggs, W. L., Sullivan, N., \& Towler, A. (2005). A measure of college student course engagement. The Journal Of Educational Research, 98(3), 184 -191.

Hembrooke, H., \& Gay, G. (2003). The laptop and the lecture: The effects of multitasking in learning environments. Journal of Computing in Higher Education, 15(1), 46 -64.

Kay, R. \& Lauricella, S. (2011). Unstructured vs. structured use of laptops in higher education. Journal of Information Technology Education: Innovations in Practice, 10, 33-42. Retrieved from http://www.jite.org/documents/Vol10/JITEv10IIPp033-042Kay840.pdf

Kokkelenberg, E., Dillon, M., \& Christy, S. (2008). The effects of class size on student grades at a public university. Economics of Education Review, 27(2), 221-223.

Kraushaar, J. M., \& Novak, D. C. (2010). Examining the effects of student multitasking with laptops during the lecture. Journal of Information Systems Education, 21(2), 241.

Kuh, G. D. (2009). The national survey of student engagement: Conceptual and empirical foundations. New Directions for Institutional Research, 2009(141), 5-20.

Kuh, G. D., \& Hu, S. (2001). The relationship between computer and information technology use, selected learning and personal development outcomes, and other college experiences. Journal of College Student Development, 42(3), 217-232.

Kulesza, J., DeHondt, G., II, \& Nezlek, G. (2010). More technology, less learning? 2010 ISECON Proceedings.

Laird, T. F., \& Kuh, G. D. (2005). Student experiences with information technology and their relationship to other aspects of student engagement. Research in Higher Education, 46(2), 211 -233.

Mandernach, B. J. (2009). Effect of instructor-personalized multimedia in the online classroom. International Review of Research in Open and Distance Learning, 10(3). Retrieved December 12, 2011, from http://www.irrodl.org/index.php/irrodl/article/view/606/1263

Mandernach, B. J., Donnelli-Sallee, E., \& Dailey-Hebert, A. (2011). Assessing course student engagement. In R. L. Miller, E. Amsel, B. Kowalewski, B. Beins, K. Keith, \& B. Peden (Eds.), Promoting student engagement, Volume 1: Programs, techniques and opportunities. Syracuse, NY: Society for the Teaching of Psychology. Retrieved December 12, 2011 from: http://www.teachpsych.org/teachpsych/pnpp

Mann, S., \& Robinson, A. (2009). Boredom in the lecture theatre: An investigation into the contributors, moderators and outcomes of boredom amongst university students. British Educational Research Journal, 35(2), 243-248.

Pearson Foundation. (2010). Survey on students and tablets. Retrieved December 12, 2011 from http://pearsonfoundation.org/downloads/PF_Tablet_Survey_Summary.pdf

Pearson Foundation. (2012). Survey on students and tablets 2012. Retrieved from http://www.pearsonfoundation.org/downloads/PF_Tablet_Survey_Summary 2012.pdf

Svanum, S., \& Bigatti, S. (2009). Academic course engagement during one semester forecasts college success: Engaged students are more likely to earn a degree, do it faster, and do it better. Journal of College Student Development, 50(1), 120-132.

Watson, R. \& Barber, C. J. (2008). Personal electronic devices in the university classroom. 2008 refereed proceedings of the Association of Business Information Systems, pp. 79-82.

Wingard, R. G. (2004). Classroom teaching changes in web-enhanced Courses: A multi-institutional study. EDUCAUSE Quarterly, 27(1), 26 -35.

Wurst, C., Smarkola, C., \& Gaffney, M. A. (2008). Ubiquitous laptop usage in higher education: Effects on student achievement, student satisfaction, and constructivist measures in honors and traditional classrooms. Computers \& Education, 51(4), 1766 -1783. 
Young, S. \& Bruce, M. (2011). Classroom community and student engagement in online courses. Journal of Online Learning and Teaching, 7(2). Retrieved December 12, 2011, from http://jolt.merlot.org/vol7no2/young_0611.htm

\section{Appendix: Survey of Mobile Device Use During Lecture}

1. I regularly use a laptop computer during lectures in this course.

Strongly Disagree

12
3

4
Strongly Agree

5

2. I regularly use a tablet during lectures in this course.

Strongly Disagree

12
3

4
Strongly Agree

5

3. I regularly use a smartphone or blackberry during lectures in this course.

Strongly Disagree

12
3

4

4. I regularly use a cellphone (Not including smartphones/blackberries) during lectures in this course.

\section{Strongly Disagree \\ 12}

3

4

5. During today's lecture, approximately what percentage of time did you spend using each of the following devices for non-course related activities?

Laptop:

Tablet:

smartphone or Blackberry: $\%$

Cellphone (Not including smartphones and blackberries):

Strongly Agree

5

6. During today's lecture did you use your laptop for any of the following activities? (Circle all that apply)

a. I did not use a laptop in class today.

b. Taking notes

c. Reading the course outline or lecture notes posted by the professor

d. Reading material related to the course other than the course outline or notes posted by the professor

e. Commenting on or discussing the content of the current lecture

f. Arranging to meet with peers outside of class for classwork

g. Working on an assignment

h. Email

i. Instant Messaging

j. Social networking (including Facebook, Twitter etc...)

$\mathrm{k}$. Watching videos (including YouTube)

1. Surfing the Internet (Not including social networking sites and video sites)

m. Arranging to meet socially with peers outside of class

n. Playing games

o. Other. Please specify:

7. During today's lecture did you use your tablet for any of the following activities? (Circle all that apply)

a. I did not use a tablet in class today.

b. Taking notes 
c. Reading the course outline or lecture notes posted by the professor

d. Reading material related to the course other than the course outline or notes posted by the professor

e. Commenting on or discussing the content from the current lecture

f. Arranging to meet with peers outside of class for classwork

g. Working on an assignment

h. Email

i. Instant messaging

j. Social networking (including Facebook, Twitter etc...)

k. Watching videos (including YouTube)

1. Surfing the Internet (Not including social networking and video sites)

m. Arranging to meet socially with peers outside of class

n. Playing games

o. Other:

8. During today's lecture did you use your smartphone or blackberry for any of the following activities? (Circle all that apply)

a. I did not use a smartphone or blackberry in class today.

b. Taking notes

c. Reading the course outline or lecture notes posted by the professor

d. Reading material related to the course not posted by the professor

e. Commenting on or discussing the content of the current lecture

f. Arranging to meet with peers outside of class for classwork

g. Working on an assignment

h. Email

i. SMS/Text messaging

j. Social Networking (Including Facebook, Twitter, etc...)

$\mathrm{k}$. Watching videos (Including YouTube)

1. Surfing the Internet (Not including social networking and video sites)

$\mathrm{m}$. Arranging to meet socially with peers outside class

n. Playing games

o. Other. Please specify:

9. During today's lecture did you use your cellphone (Not including smartphones and blackberries) a. for any of the following activities? (Circle all that apply)

b. I did not use a cellphone in class today.

c. Taking notes

d. Reading the course outline or lecture notes posted by the professor

e. Reading material related to the course not posted by the professor

d. Commenting on or discussing the content of the current lecture

f. Arranging to meet with peers outside of class for classwork

g. Working on an assignment

h. Email

i. SMS/Text Messaging

j. Social Networking (including Facebook, Twitter etc...)

$\mathrm{k}$. Watching videos (including YouTube)

1. Surfing the Internet (not including social networking and video sites)

$\mathrm{m}$. Arranging to meet socially with peers outside of class

n. Playing games

o. Other. Please specify: 


\section{Biographies}

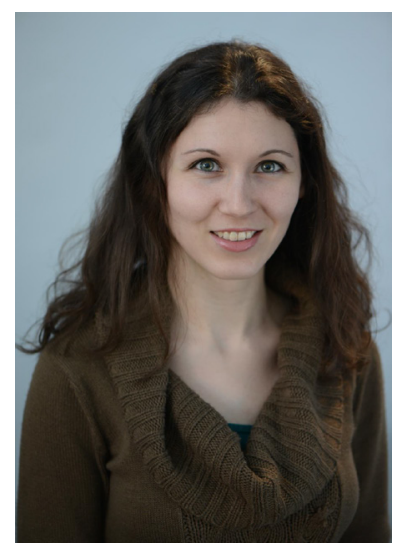

Gwendolyn Witecki is a graduate student in the School of Computer Science at the University of Guelph. Her research interests include student engagement and mobile device use and student engagement in distance education. Prior to beginning graduate studies, Gwendolyn developed an interest in student engagement through her experiences teaching at various levels of education, and developing instructional material for both academic and extracurricular classes. Other areas of research interest include challenges surrounding the use of mobile phones by the elderly, and developing touch interfaces for elderly mobile phone users.

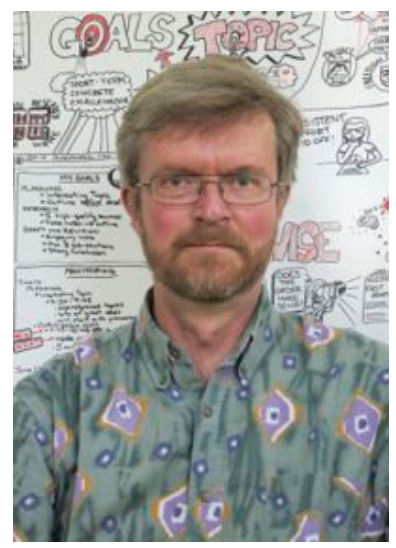

Blair Nonnecke is an Associate Professor in the School of Computer Science at the University of Guelph, and a usability professional with particular interests in user-centred design (UCD), telematics, and lurkers in online communities. Recent research has focused on the discord between usability research and its practice; and student self-efficacy and online engagement. Prior to joining the University of Guelph, Blair was the Director of Usability at Maptuit Corp. While there he was responsible for user-interface architecture, requirements analysis, competitive reviews, discount usability, expert review, and research into online maps and directions. He is well acquainted with the issues of incorporating HCI into software engineering and marketing processes where his interest in people and his training in the technical aspects of computers and HCI have been put to good use. 